\section{A national study of cross infection control: 'are we clean enough?'}

\author{
R. Shah, ${ }^{1}$ J. M. Collins, ${ }^{2}$ T. M. Hodge ${ }^{3}$ and E. R. Laing ${ }^{4}$
}

VERIFIABLE CPD PAPER

IN BRIEF
- Provides readers with information about
the cross infection control procedures
in place within UK hospital orthodontic
departments.
- Investigates training, decontamination
and disposal of waste.
- Suggests some areas where
improvements could be made.
Provides readers with a 'refresher' on
cross infection control policies and
procedures.

\begin{abstract}
Objective To establish what cross infection control policies and procedures are in place within UK orthodontic departments and how they compare with recommended guidelines. Design A hospital-based cross-sectional study investigating UK orthodontic departments between March 2007 and January 2008. Subjects and methods The main outcome measure was a questionnaire constructed for the study, based on current cross infection control guidelines. All orthodontic departments within district general hospitals were invited to participate via email and the response rate was $48 \%$. Results Five key areas were explored, which included a) training, education and personal protection, b) the clinical environment, c) decontamination of instruments, d) decontamination of appliances and impressions and e) disposal of waste. Ninety-eight percent of departments provided training in cross infection control and $98 \%$ also had a policy to check staff immunisation status. With respect to the clinical environment, $97 \%$ of the departments surveyed had separate 'clean' and 'dirty' zones. Half of all departments used central sterile services departments (CSSD) for instrument sterilisation. Seventy-eight percent of departments had a policy to decontaminate impressions/appliances at the chairside and all departments used 'yellow bags' for clinical waste and puncture-proof containers for sharps waste. Conclusions UK orthodontic departments have implemented policies and procedures which would ensure a high standard of cross infection control. In particular, this related to the decontamination of surfaces and instruments, the use of personal protection and disposal of clinical waste. Most departments had policies and procedures in place for staff education and training in cross infection control and personal protection.
\end{abstract}

\section{INTRODUCTION}

The nature of dentistry is such that both patients and healthcare professionals may be exposed to pathogens through contact with blood, oral and/or respiratory secretions. Cross infection control aims to prevent this transmission of infection by breaking the cycle of infection as illustrated in Figure 1. The General Dental Council in Standards for dental professionals states that dental professionals are expected to '...provide a

${ }^{1 *}$ Lecturer in Orthodontics, UCL Eastman Dental Institute, 256 Gray's Inn Road, London, WC1X 8LD; ${ }^{2}$ Fixed Term Training Appointment in Orthodontics, Eastman Dental Hospital, University College London Hospitals NHS Trust, 256 Gray's Inn Road, London, WC1X 8LD and Kingston Hospital NHS Trust, Galsworthy Road, Kingston upon Thames, Surrey, KT2 70B: ${ }^{3}$ Consultant in Orthodontics, Leeds Dental Institute, Clarendon Way, Leeds, LS2 9LU; ${ }^{4}$ Specialist in Orthodontics, Eastman Dental Hospital, University College London Hospitals NHS Trust, 256 Gray's Inn Road, London, WC1X 8LD

*Correspondence to: Miss Rishma Shah

Email:r.shah@eastman.ucl.ac.uk

\section{Refereed Paper}

Accepted 13 July 2009

DOI: 10.1038/sj.bdj.2009.824

${ }^{\circledR}$ British Dental Journal 2009; 207: 267-274 good standard of care based on available up-to-date evidence and reliable guidance. ${ }^{1}$ Failure to comply with appropriate standards might lead to a charge of serious professional misconduct. Incorporating evidencebased infection prevention and control advice into routine clinical care activities is believed to be important in reducing the incidence of preventable healthcare-associated infections. ${ }^{2}$ Consequently, guidelines to facilitate the implementation of this have been devised by NICE.

Specifically for dentistry, the British Dental Association (BDA) A12 advice sheet, developed with the Department of Health in England, is consistent with the most recent cross infection control policies in the National Health Service and is widely quoted. ${ }^{4}$ It encompasses the main areas of cross infection control: personal protection, surgery design, equipment, routine procedures, clinical waste and emerging infections. It is a concise, well-presented document that defines where dentists' obligations lie within health and safety and employment law.
Cross infection control will always be an important area of concern as new and emerging pathogens are isolated and especially as drug resistance increases. The aims of this national study on cross infection control were to:

1. Establish what policies and procedures are currently in place within orthodontic departments in the UK and to compare them with the recommended guidelines (Phase 1)

2. Undertake a blind observational study to establish the compliance of the team with their current departmental cross infection control policies and procedures (Phase 2).

\section{PHASE 1: DESIGN OF STUDY AND METHODS}

This paper will focus upon Phase 1, which was undertaken between March 2007 and January 2008 and is now complete. The results and recommendations have been disseminated to each participating hospital. Phase 1 encompassed a questionnaire- 
based study to establish the cross infection policies and procedures established within orthodontic departments in the UK. The questionnaire was constructed to cover the main areas of cross infection control:

1. Training, education and personal protection

2. Clinical environment

3. Decontamination of instruments

4. Decontamination of appliances and impressions

5. Disposal of waste.

A focus group was formed to devise the questionnaire, which was based on the BDA A12 advice sheet and was first piloted in the South-West Thames region. Following amendments, all orthodontic departments within district general hospitals in the UK were invited to take part by email. In total, 133 questionnaires were posted and sent by email to the respective cross infection officers. Six weeks were given for completion of the questionnaire and two email reminders were sent to the departments that had failed to meet the deadline. The final response rate was $48 \%$.

In the next section the current evidence regarding the five key areas of cross infection control will be discussed in turn. This will be followed by the results of the national questionnaire.

\section{CURRENT EVIDENCE}

\section{Training, education and personal protection}

\section{Training and education}

In accordance with the Health and Safety at Work Act 1974, the employer has a duty of care towards their employees, patients and others who visit the surgery, to provide a safe place of work, to train staff appropriately and to provide personal protective equipment. The General Dental Council has also issued guidance on the areas of education, training and remaining up to date. ${ }^{1}$ All members of the dental team should be trained in cross infection control policies and procedures, which will then equip them to understand how infections are transmitted, what personal protection is required and when to use it, and what to do in event of situations such as inoculation injuries.

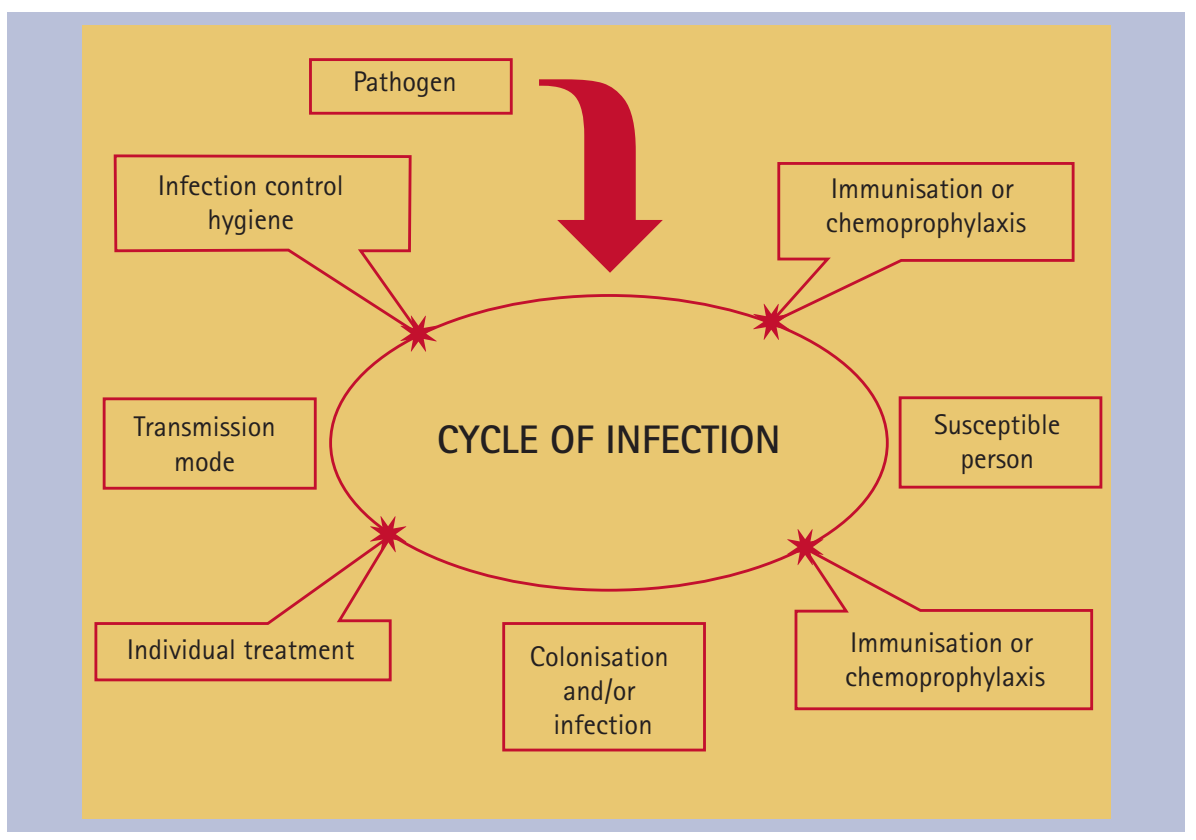

Fig. 1 The cycle of infection and how it may be broken

\section{Personal protection}

(i) Medical history

It is important to take a medical history every time a patient is seen. ${ }^{5}$ However, the British Orthodontic Society (BOS) advice sheet suggests updating the medical history regularly, although not necessarily at every visit for orthodontic patients undergoing treatment. ${ }^{5}$

\section{(ii) Staff immunisation}

All dental staff should be inoculated against diseases preventable by vaccines and evidence of this must be held by the employer. It is recommended that anti-HBs levels measured 2-4 months after completion of the immunisation course of $\geq 10$ $\mathrm{mIU} / \mathrm{ml}$ will provide protection against hepatitis B infection. ${ }^{6}$ In October 2007, the Department of Health issued guidance to the NHS on the screening of new healthcare workers for tuberculosis and hepatitis B. ${ }^{7}$ Furthermore, those clinicians involved in exposure-prone procedures must be cleared for hepatitis C and HIV?

(iii) Personal protection in the surgery In considering appropriate methods of personal protection, the mode of transmission of infections should be borne in mind. These are: direct contact with blood or bodily fluids, indirect contact with a contaminated instrument or surface, and contact of the mucosa of the eyes, nose or mouth with splatter or inhalation of airborne microorganisms.
Hand hygiene is one of the most important factors in cross infection control in healthcare settings, as hands are one of the most common modes of pathogen transmission. ${ }^{8}$ A methodological procedure for handwashing should be adopted.,10 Equally, waterless alcohol-containing preparations, also known as alcohol handrubs, can offer fast and effective antimicrobial action provided the hands are not visibly soiled. Good quality, non-sterile, well-fitting, hypoallergenic, non-powdered gloves should always be worn. ${ }^{11}$

The use of personal protective equipment (PPE), such as protective clothing, eyewear and disposable gloves, provides protection against foreign bodies, splatter and aerosols that may arise during operative dentistry and the cleaning of instruments. Masks do not confer complete protection from microorganisms, but do stop splatter from contaminating the face. ${ }^{12,13}$ They should be changed after every patient, not pulled down or re-used. ${ }^{13,14}$ Eye protection should be worn. High-necked tunics/uniforms are recommended to protect from the splatter generated from operative dentistry. The Department of Health suggests that gentleman's ties should not be worn when treating patients. ${ }^{14}$

\section{(iv) Inoculation injuries}

Sharps injuries should be taken seriously, as they are the most likely route for transmission of blood borne viral infections in dentistry. Each surgery/department should have 
a written visible policy for the management of sharps and significant splashes into the eye or onto broken skin. There should be minimal delay following injury for advice on risk assessment and prophylaxis against HIV and hepatitis B infection, as HIV postexposure prophylaxis, if required, should be given within one hour to achieve maximum preventive benefits. ${ }^{15}$

\section{Clinical environment}

In accordance with BDA A12 advice sheet, ${ }^{5}$ the clinical environment should be simple, uncluttered and well ventilated. Work surfaces and floor coverings should be impervious and easy to clean and disinfect. Clean and dirty zones should be clearly identified and ideally instruments should be decontaminated in a room away from the surgery. All water and air-lines should be fitted with anti-retraction valves to help prevent contamination of the lines.

Furthermore, the suction apparatus and spittoon need to be flushed daily with a non-foaming disinfectant/detergent. It has been recommended that the dental unit waterlines should be drained at the end of the working day and flushed through to reduce the microbial load in dental water systems. However, it has been suggested that strategies other than flushing are needed to improve the water quality, ${ }^{12,16}$ as a biofilm in dental waterlines can still exist. ${ }^{17}$ In particular, important pathogens such as Legionella spp are associated with biofilms and have been demonstrated in dental waterlines. ${ }^{18}$ Recent regulations have been issued with regards to this. ${ }^{19}$ Methods that can be employed to reduce the risk include ensuring that dental units are fitted with anti-retraction valves and terminal flush devices and have an independent bottled water supply to help to control microbial contamination. Chemical treatments can aid the removal or inactivation of biofilms present in dental waterlines.

\section{Decontamination of instruments}

Decontamination is a combination of processes, including cleaning, sterilisation or disinfection and storage, used to render a reusable item safe. It is a requirement of the Provision and Use of Work Equipment Regulations 1998 that everyone who operates, supervises or manages work equipment be trained adequately. ${ }^{20}$ It is the view of the Department of Health that central sterile services departments (CSSD) provide a superior service to local decontamination in dental surgeries. ${ }^{21}$ However, it has been recognised that this is not always practicable and alternative guidance has been issued. ${ }^{22}$

The cleaning of surgical instruments is necessary to ensure effective disinfection and sterilisation. ${ }^{23}$ Instruments can be handwashed or ultrasonic cleaners and washers can be used. Using automated washing methods rather than manual cleaning is considered to be more efficient and less likely to cause inoculation injuries. ${ }^{24}$

For sterilisation the method of choice is the autoclave. The relevant cycle parameters for orthodontic instruments are $134-137^{\circ} \mathrm{C}$ for a minimum holding time of 3 minutes..$^{25}$ Nonvacuum bench top sterilisers, in which air is passively displaced downwards by steam, are only suitable for processing instruments that are not wrapped and are solid. ${ }^{26}$ Where instruments are placed in pouches or are hollow, for example, handpieces, these are best sterilised using a vacuum-phase autoclave. ${ }^{27}$ Sterilisers must be validated before use, maintained, operated correctly and constantly monitored in order to ensure that consistent sterilisation is being achieved. ${ }^{26}$

The theoretical risk of prion transmission via surgical instruments is of concern. ${ }^{28}$ Plasma cleaning may offer a safe and effective method for decontamination of dental instruments potentially contaminated with prion proteins. ${ }^{29}$ The Chief Dental Officer for England has given guidance with regard to the re-use of instruments and the risks of variant Creutzfeldt-Jakob disease. ${ }^{30}$ Guidance from the MHRA clearly states that devices intended for single use should never be reprocessed. ${ }^{31}$

\section{Decontamination of appliances and impressions}

Dental impressions can become contaminated with saliva and blood containing bacterial and viral pathogens, which can infect casts poured against them..$^{32,33}$ Components of both fixed and removable appliances can become colonised by microorganisms after a certain time in the mouth. ${ }^{34}$ The disinfection process should be effective in removing pathogens, ${ }^{35}$ however there should be no adverse effect on the impression material or appliance. The majority of studies have demonstrated that simply rinsing in water is not enough to remove adherent pathogens. ${ }^{33,36,37}$

For most impressions and appliances, an appropriate decontamination regime comprises rinsing in cold water to remove any blood, saliva or debris followed by immersion in a fresh chlorine-based solution (1,000 ppm) for 10 minutes. Spraying with disinfectant is not advocated due to the inhalational risk. ${ }^{5}$ Taylor et al. ${ }^{38}$ found both sodium hypochlorite and a disinfecting solution, Perform ${ }^{\circledR}$, were effective in the elimination of Staphylococcus aureus. Furthermore, it has been suggested that rinsing should also take place after disinfection to remove any residual disinfectant, which may affect the surface of the stone cast. ${ }^{39}$

\section{Disposal of clinical waste}

Clinical waste is waste that is contaminated with blood, saliva or other bodily fluids and which may prove hazardous to any person coming into contact with it. ${ }^{40}$ All healthcare workers have a legal responsibility to dispose of waste safely. Under the Hazardous Waste Regulations 2005, waste should be segregated into clinical and non-clinical waste. ${ }^{41}$ Clinical waste should be bagged in labelled yellow bags of 225 gauge and be no more than three-quarters full to prevent spillage, and arrangements should be made for collection and safe disposal. Sharps must always be placed into a sharps container (conforming to UN3291 and BS7320 standards) at the point of use by the user, and never be placed into a waste bag of any kind.

\section{QUESTIONNAIRE RESULTS}

Throughout these results, percentages are given in parentheses and are based on the total number of departments that answered a particular question, as occasionally not all questions were answered in every questionnaire.

\section{Training, education and personal protection}

\section{Training and education}

The majority of departments provided some form of training in cross infection control $(98 \%, \mathrm{n}=64)$. Thirty-eight percent reached the accepted standard of training at the start of employment and had regular updates (Fig. 2) $(\mathrm{n}=61)$. 


\section{Personal protection}

\section{(i) Medical history}

Ninety-eight percent of respondents obtained a medical history at the first appointment $(n=64)$. At review and treatment visits, far fewer departments had a policy in place to obtain medical histories (26\% and 13\% respectively).

\section{(ii) Staff immunisation}

The majority of respondents stated it was the responsibility of occupational health to check immunisation status $(75 \%, n=64)$. Fifty-two percent of departments had a policy in place to check immunisation status on commencing post $(n=64)$.

(iii) Personal protection in the surgery In $66 \%$ of departments $(n=64)$, it was policy to remove all hand jewellery for patient treatment. In 98\% of departments $(n=64)$, it was policy to routinely wear gloves for all patients and 100\% changed gloves between patients. Ninety-eight percent of departments $(n=64)$ responded that it was their policy to wash/disinfect hands before and after wearing gloves. The most popular media used for handwashing/disinfection were anti-microbial soap and alcohol gel, as used by $97 \%$ of departments.

In $78 \%$ of departments ( $n=64$ ), it was policy for all staff to wear eye protection. Nearly one third (31\%) of departments wore eye protection for high-risk procedures only. One hundred percent of departments ensured that patients wore safety glasses $(n=63)$. It was not departmental policy to wear facemasks in almost two thirds of departments $(65 \%, n=62)$. In terms of surgery clothing, $98 \%$ of nurses, $34 \%$ of clinicians and 71\% of technicians wore standard surgery clothing.

\section{(iv) Inoculation injuries}

In the event of inoculation injuries, 95\% of departments $(n=63)$ had local arrangements set up for the management of such injuries. Of those with procedures in place ( $n=60), 69 \%$ had these clearly displayed within the department.

\section{Clinical environment}

\section{Surface decontamination}

Out of 63 departments that responded, $97 \%$ said that it was their policy to have 'clean' and 'dirty' zones. With respect to

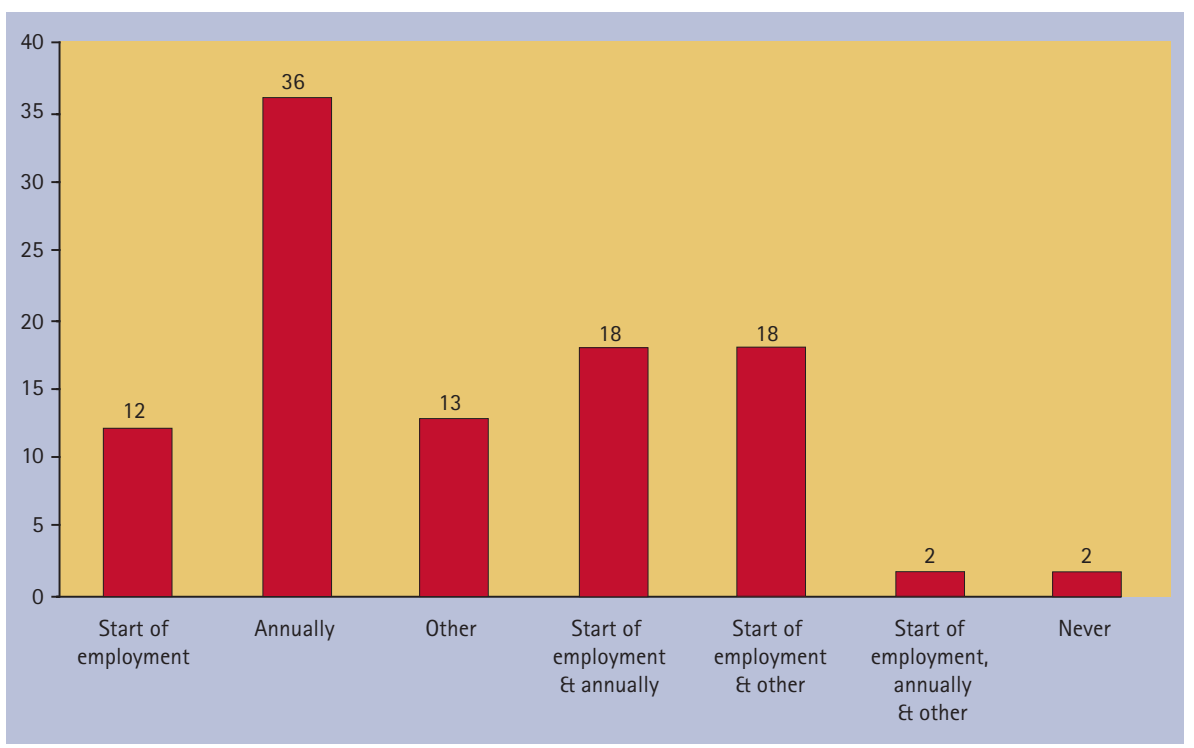

Fig. 2 Bar chart to show how often staff receive training in cross infection control

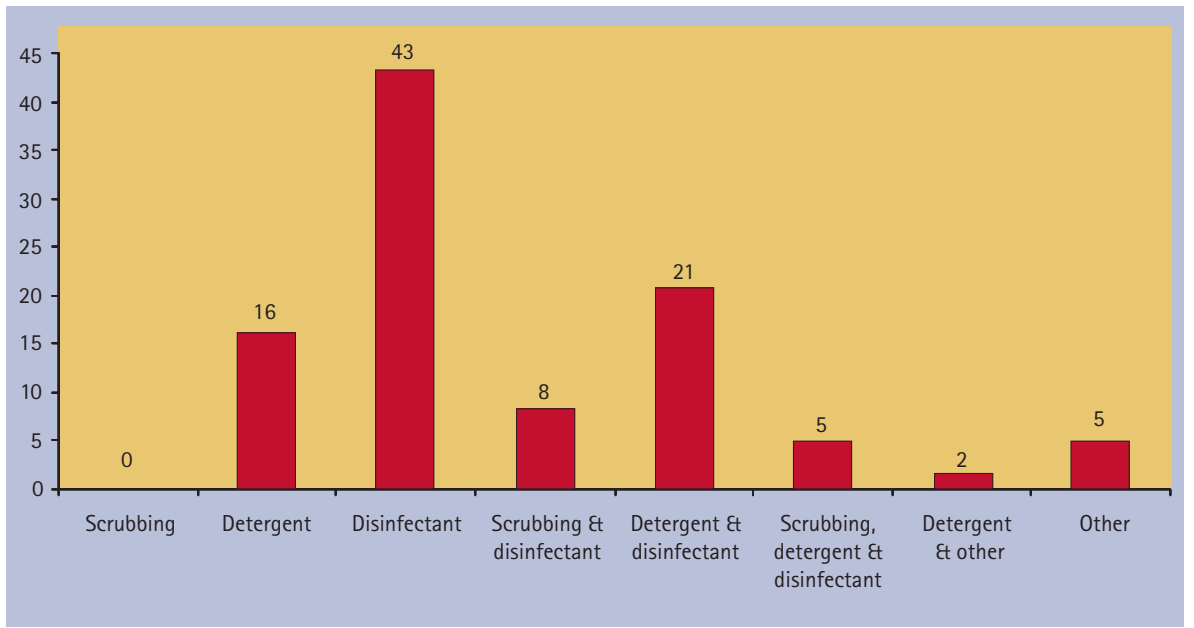

Fig. 3 A bar chart to show departmental policy on the decontamination of surfaces

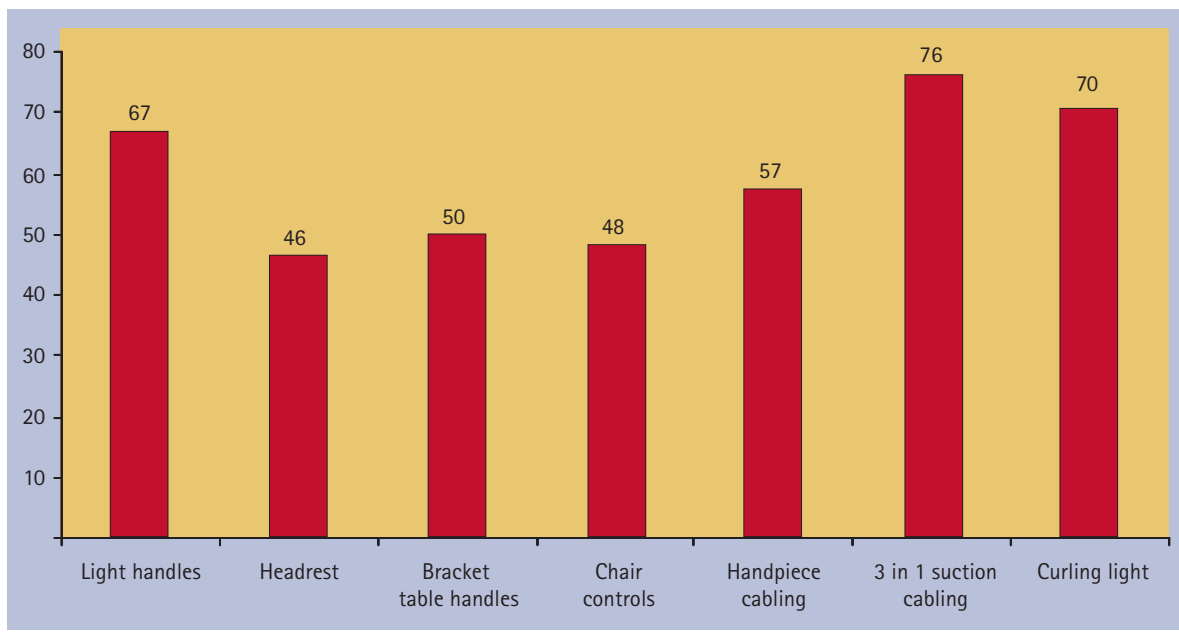

Fig. 4 A bar chart to show the surfaces covered by barrier methods

departmental policy on surface decontamination, the results are illustrated in Figure 3 ( $\mathrm{n}=63$ ).

Disposable impervious coverings were used by $79 \%$ of departments $(n=63)$. The surfaces most commonly covered included the suction cabling, followed by the curing light and light handles (Fig. 4). Ninety percent of these departments had a policy to change these barriers between patients, the remainder (10\%) changed them either at the start of the day or the start of a new session. 


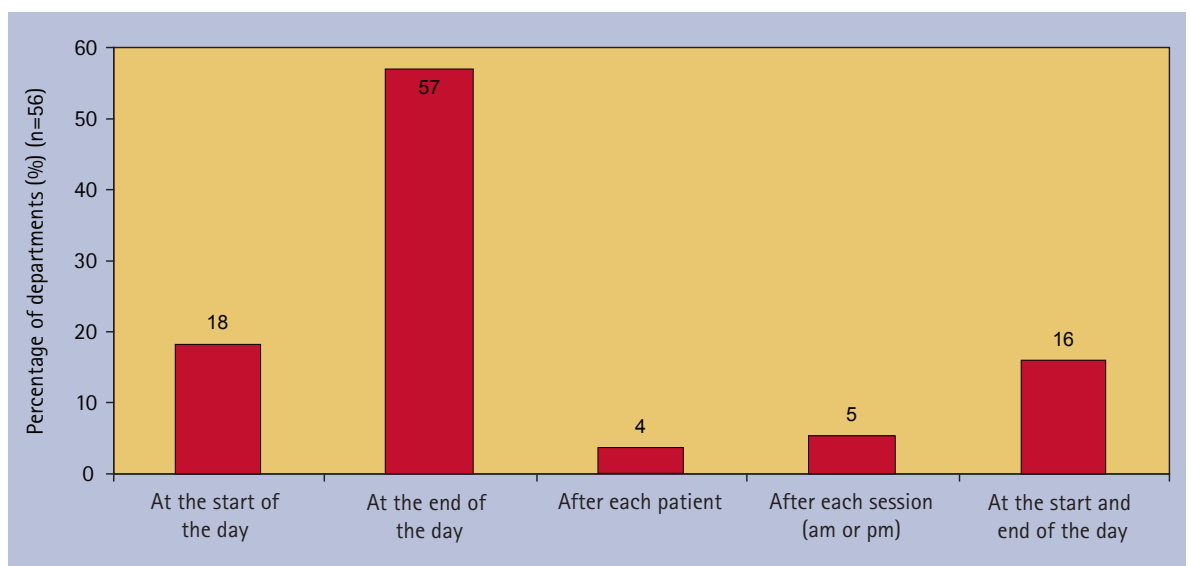

Fig. 5 Of those who disinfect dental waterlines and suction tubing, a bar chart to show when it is policy to carry this out

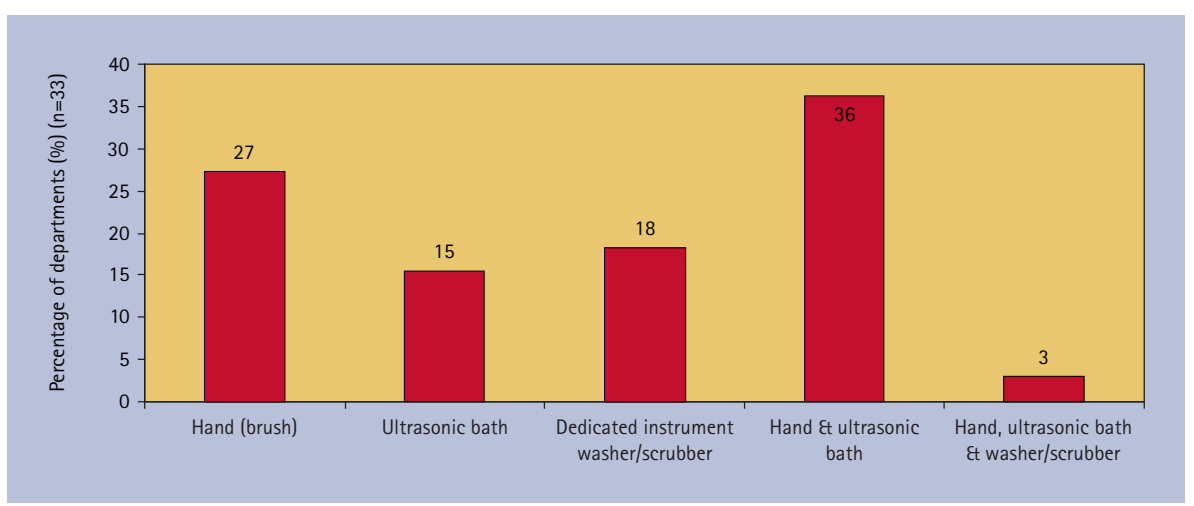

Fig. 6 A bar chart to show departmental policy on cleaning of instruments

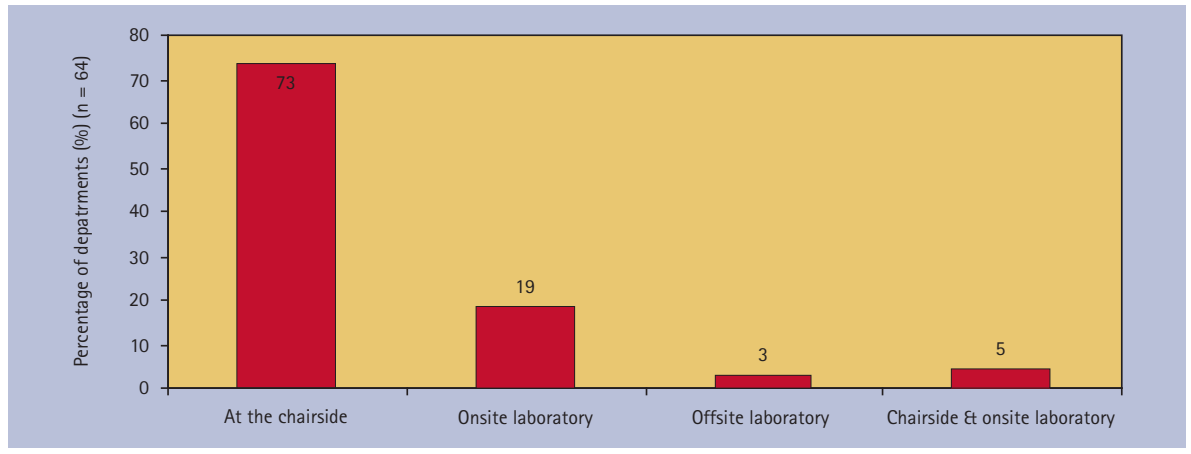

Fig. 7 Bar chart to show departmental policy in decontamination of appliances and impressions

Where barrier methods were not used, 96\% ( $\mathrm{n}=50$ ) had a policy of routinely decontaminating dirty surfaces, and $94 \%$ of these departments did so after each patient.

\section{Disinfection of dental waterlines and suction tubing}

Ninety-two percent of departments stated that it was policy to disinfect the dental waterlines and suction tubing, and of the 8\% who answered 'no', some stated that it was policy to just disinfect the suction rather than the waterlines $(n=64)$. Figure 5 illustrates when respondents disinfected their dental waterlines and tubing $(\mathrm{n}=56)$. It was policy to flush through the waterlines at the start of the day in $53 \%$ of the departments surveyed $(n=61)$. Regarding departmental policy for filling and draining the water bottles, 61\% had a policy to do so on a daily basis $(\mathrm{n}=57)$.

\section{Decontamination of instruments}

\section{Pre-sterilisation cleaning}

Of those departments $(\mathrm{n}=33)$ undertaking pre-sterilisation cleaning, a combination of methods was used (Fig. 6).

\section{Sterilisation}

Of the departments surveyed $(n=64)$, $50 \%$ used CSSD for their instrument sterilisation. Thirty-seven percent used a departmental bench-top steriliser and $13 \%$ used a combination of departmental and CSSD sterilisation. Of those who used departmental sterilisation ( $\mathrm{n}=24$ ), it was policy to drain the autoclave at the end of the day in 71\% of departments and 83\% had policy in place to keep a direct record of successful sterilisation.

\section{Decontamination of handpieces and burs}

All departments had policy in place to decontaminate handpieces after each patient. With respect to flushing of handpieces connected to waterlines, there was some discrepancy between departments in the frequency of doing so. Thirty-five percent had a policy to flush through handpieces before each patient, but 39\% never flushed their handpieces $(n=62)$.

Fifty-nine percent of departments had a policy to use single-use burs ( $n=64)$. Three percent did not have a policy on bur decontamination and the remainder of departments had policy in place to decontaminate burs after each use.

\section{Single-use items}

A variety of single-use items were used, with plastic beakers, saliva ejectors and prophy cups being the most common. Approximately two thirds of departments re-used orthodontic bands. Of the 'other' single-use items, some departments commented that bands with attachments were disposed of, whereas plain bands were sterilised and re-used. It was policy in $61 \%$ of departments to dispose of any unused modules/elastomerics, but not in the remaining 39\% $(n=64)$.

\section{Decontamination of appliances and impressions}

The majority of departments (73\%) had policy in place to decontaminate impressions and appliances at the chairside (Fig. 7) (n=64). Of those who decontaminated at the chairside, $67 \%$ of departments informed the laboratory in writing that the impression/appliance had been decontaminated, whereas the remainder did not have policy in place to ensure this was done (33\%, $\mathrm{n}=51)$.

The decontamination procedure, whether at the chairside or in the laboratory, varied among the departments surveyed; 
the majority (61\%) had a policy in place to immerse the impression/appliance in manufacturer-approved disinfectant (Fig. 8) ( $\mathrm{n}=62)$.

\section{Disposal of clinical waste}

One hundred percent of departments used 'yellow bags' for clinical waste and 100\% of departments had puncture-proof containers for sharps waste $(n=64)$. Just over half of the departments (54\%) had a policy to dispose of clinical waste bags/sharps bins when they were less than three-quarters full. Thirty-eight percent disposed of them when they were less than two-thirds full, 5\% when less than half full and 3\% when completely full. In approximately two-thirds (67\%) of departments, the policies and procedures on clinical waste management were clearly displayed within the department for all staff to observe $(n=64)$.

\section{DISCUSSION}

Cross infection control forms an important part of practice for all healthcare professionals and remains one of the most costeffective medical interventions available. The General Dental Council states that all dentists, as part of their continuing professional development (CPD), must complete at least five hours of verifiable training in disinfection and decontamination per fiveyear cycle. ${ }^{1}$ The purpose of the first phase of this national study was to investigate what cross infection control policies and procedures were in place within UK orthodontic departments. The 'gold standards' for comparison were the NICE recommendations ${ }^{3}$ and the British Dental Association A12 advice sheet. 5

\section{Training, education and personal protection}

Of the departments surveyed, 98\% provided some form of training in cross infection control for staff. However, it appears training standards fell short of the required standard in a large number of departments (62\%), as training did not always encompass the five main areas of cross infection control. Ideally, there should be mandatory staff training in cross infection control on commencing employment and subsequent updates scheduled for the whole department, such as on an annual basis, or whenever new policies are introduced that necessitate a change of practice.

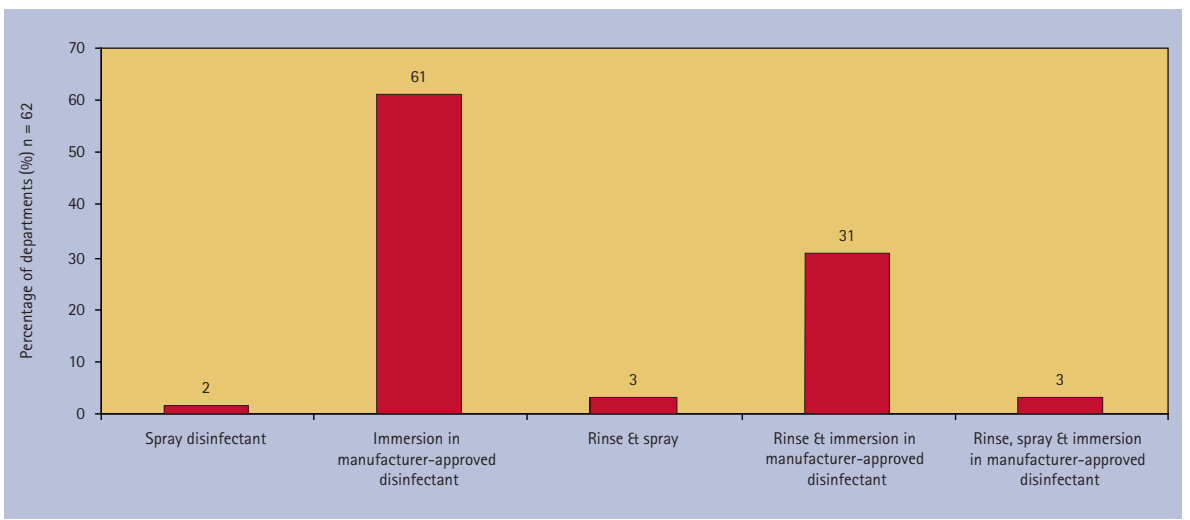

Fig. 8 Departmental policy on the decontamination of impressions and appliances

\section{Table 1 Suggested areas for improvement in cross infection control}

Mandatory training upon commencing employment with regular updates.

Staff immunisation status and post-vaccination blood test results should be obtained and retained at start of employment.

Medical history should be checked and regularly updated.

Policies such as the management of inoculation injuries should be clearly displayed in the department.

Pictorial images, eg handwashing technique, above sinks is a good means of encouraging staff to comply with accepted practice.

All departments should adopt 'clean' and 'dirty' zones, effective two-stage surface disinfection, greater use of barrier methods and regular flushing of water lines.

Personal protection during pre-sterilisation cleaning should be adopted.

The outcome of every autoclave cycle should be recorded.

No stagnant water left in ultrasonic baths or autoclaves overnight.

Single-use items should be used whenever possible.

Inquiring about the medical history of all patients is essential before the start of treatment and during treatment. Not checking a medical history during treatment could result in increasingly common conditions, such as latex allergies, being overlooked. Three percent of departments did not have a policy in place to check staff immunisation, which is surprising given that compliance with personal protection is a part of staff contracts of employment.

Policies and procedures for wearing eye protection (78\%) and facemasks (65\%) were less common, thus exposing clinicians to blood and saliva splatter. Ninetyfive percent of departments have local policies in place for the management of inoculation injuries, but contrary to the recommendations of the BDA A12 advice sheet, they were not clearly displayed in almost one in three departments.

\section{Clinical environment}

Investigating the layout of the clinical environment, it was encouraging that 97\% of the departments surveyed had policy in place for separate 'clean' and 'dirty' zones in order to minimise the chance of cross-contamination.

However, there were varying policies regarding surface decontamination. This should involve a two-stage process of vigorous cleaning with detergent followed by application of a disinfectant solution, but only 5\% of departments had this policy in place. Ninety-four percent of departments had a policy to disinfect surfaces after each patient, however far fewer disinfected at the start of each day and each session, which is also necessary. Barrier methods proved to be a popular method of preventing cross-contamination and were used by $79 \%$ of departments. Of the $21 \%$ who did not use barrier methods, it was policy in $96 \%$ to routinely decontaminate surfaces between patients.

Almost all departments (92\%) had a policy in place to disinfect dental water lines and suction tubing. This is of great importance, as microorganisms can 
multiply in the waterlines and infected material can become aspirated back into the tubing, creating a cross infection risk. There are a variety of commercially available biocides for disinfecting the water lines and suction, such as hydrogen peroxide (eg Orotol $^{\oplus}$, Oxygenol), citric acid (eg Alpron, Alprojet), and electrochemically activated water (eg Optident Sterilox). The Health and Safety Commission recommends the use of disinfectant either daily or weekly to disinfect the waterlines according to the manufacturer's instructions or continuously via automated dosing systems.

Flushing through tubing at the start of the day in dental units which are not drained at night will help reduce the bacterial load caused by overnight water stagnation, but just over half of departments had a policy in place to do this. Flushing for 20-30 seconds between patients helps to prevent cross-contamination by removing any suck-back of oral fluids that have bypassed the anti-retraction valves in the waterlines, yet only 5\% of departments had a policy to ensure this was undertaken.

\section{Decontamination of instruments}

A range of methods was used nationally for pre-sterilisation cleaning, with washer/ scrubbers utilised in approximately one in five units. As anticipated, a combination of departmental and CSSD autoclaving was undertaken. Eighty-three percent of departments had a policy to record the success of the autoclaving cycle, which is an important means of monitoring eff1cacy and ideally all departments should be undertaking this procedure.

All departments had a policy in place to decontaminate handpieces after use, but there were varying policies regarding frequency of flushing through them. Thirtynine percent of departments did not have a policy to flush handpieces and this is an issue that needs to be addressed.

Many departments were using disposable items, such as saliva ejectors, impression trays and burs. Fifteen years ago, Scully et al. ${ }^{42}$ in a survey of 6,588 NHS general dental practitioners, found that only $81 \%$ routinely used autoclaves and less than a half of respondents sterilised or disinfected handpieces after each patient use, so improvements have been made over the last 15 years.

\section{Decontamination of appliances and impressions}

The decontamination of impressions and appliances is an important process required to ensure that the dental team, which includes the dental technician, are protected from harmful pathogens. Indeed, occupational infection of dental laboratory technicians with hepatitis B has been reported.$^{43}$ It is the dentist's responsibility to ensure that all impressions and appliances are cleaned and disinfected before being sent to the laboratory. ${ }^{5}$ In this study, 78\% of orthodontic departments had policy in place to carry out chairside decontamination, but this information was not always communicated to the laboratory. Therefore, it is not surprising that in another study, 94\% of laboratories routinely decontaminated their impressions, demonstrating a poor use of resources. ${ }^{44}$ This matter could be simply rectified by effective communication.

\section{Disposal of clinical waste}

All departments surveyed used 'yellow bags' and sharps bins and 97\% discarded them when three-quarters full, which is the correct procedure. Only one in three departments clearly displayed the policies and procedures for waste management. There is a need to improve the existing management of cross infection control through the provision of formal mandatory training for all staff, clearly displaying policies and procedures on waste management in each department, and dissemination of cross infection control manuals encompassing all published recommendations and departmental policies.

\section{CONCLUSIONS}

Generally, UK orthodontic departments had implemented policies and procedures as recommended by the BDA and NICE, which would ensure a high standard of cross infection control. In particular, this related to the decontamination of surfaces and instruments, the use of personal protection, and training and education in cross infection control. Suggested areas of improvement can be found in Table 1 . Comparison with other studies is always difficult, as highlighted by Gordon et al. ${ }^{47}$ in a systematic review of adherence to cross infection control guidelines in dentistry; this is due to differences in study design, targeted participants, sample sizes and outcome measures. Nonetheless, bearing in mind that the results from this audit are based on the questions posed and the accuracy to which they are answered, it was still possible to demonstrate that the majority of departments compared favourably to those investigated in other studies. ${ }^{43,45,47}$

We would like to thank the British Orthodontic Society and Bonjela for sponsoring this national study, Mr Lee Standen for the data analysis, and Miss Karen Clarke, Miss Claire Hepworth and the orthodontic departments in the South-West Thames region for their assistance with the pilot study.

1. General Dental Council. Standards for dental professionals. London: GDC, 2005.

2. Haley R W, Culver D H, White J W et al. The efficacy of infection surveillance and control programs in preventing nosocomial infections in US hospitals. Am J Epidemiol 1985; 121: 182-205.

3. National Insitute for Health and Clinical Excellence. Infection control - prevention of healthcare-associated infections in primary and community care. London: NICE, 2003.

4. British Dental Association. Infection control in dentistry. Advice Sheet A12. London: BDA, 2003.

5. British Orthodontic Society Development and Standards Committee. Advice sheet 21: medical history guidance. London: BOS, 2005.

6. Centers for Disease Control and Prevention. Immunization of health-care workers: recommendations of the Advisory Committee on Immunization Practices (ACIP) and the Hospital Infection Control Practices Advisory Committee (HICPAC). MMWR Recomm Rep 1997; 46(RR-18): 1-42.

7. Department of Health. Health clearance for tuberculosis, hepatitis B, hepatitis C and HIV: new healthcare workers. London: Department of Health, 2007.

8. Stone S P. Hand hygiene-the case for evidencebased education. J R Soc Med 2001; 94: 278-281.

9. Ayliffe G A J, Lowbury E J L, Geddes A M, Williams J D. Control of hospital infection - a practical handbook. 3rd ed. London: Chapman and Hall Medical, 1992

10. National Patient Safety Agency NPSA/PASA Hand hygiene project. In NPSA/PASA Reports \&t Documents. NPSA, 2004.

11. The Council of the European Communities. Council Directive 93/42/EEC Medical Devices 1993.

12. Kohn W G, Collins A S, Cleveland J L, Harte J A, Eklund K J, Malvitz D M; Centers for Disease Control and Prevention. Guidelines for infection control in dental health-care settings - 2003. MMWR Recomm Rep 2003; 52(RR-17): 1-61.

13. Miller C H, Palenik C J. Infection control and management of hazardous materials for the dental team. 3rd ed. Philadelphia: Elsevier/Mosby, 2005.

14. Department of Health. Uniforms and workwear: an evidence base for developing local policy. London: Department of Health, 2007

15. Department of Health. HIV post-exposure prophylaxis. London: Department of Health, 2004.

16. Centers for Disease Control and Prevention. Recommended infection control practices for dentistry, 1993. MMWR Recomm Rep 1993; 42(RR-8): 1-12.

17. Williams J $F$, Johnston $A$ M, Johnson $B$, Huntington M K MacKenzie C D. Microbial contamination of dental unit water lines: prevalence, intensity and microbiological characteristics. J Am Dent Assoc 1993; 124: 59-65.

18. Williams H N, Paszko-Kolva C, Shahamat M, Palmer C, Pettis C, Kelley J. Molecular techniques reveal high prevalence of Legionella in dental units. JAm Dent Assoc 1996; 127: 1188-1193.

19. Health and Safety Commission. The control of 
Legionella bacteria in water systems. Approved code of practice and guidance. London: Health and Safety Commission, 2000.

20. HMSO. Provision and Use of Work Equipment Regulations, 1998.

21. NHS Estates. A protocol for the local decontamination of surgical instruments. London: Department of Health, 1999.

22. Department of Health. National standards, local action: health and social care standards and planning framework 2005/6-2007/8. London: Department of Health, 2004.

23. Lowe A H, Bagg J, Burke F J T, MacKenzie D, McHugh S. A study of blood contamination of Siqveland matrix bands. Br Dent J 2001; 192: 43-45.

24. Crispin J. Cross infection - gambling against the odds. London: British Dental Health Foundation, 2004

25. Dowell T B. The problems of cross-infection in dentistry. Br Dent J 1986; 160: 131-134.

26. Medical Devices Agency. Benchtop steam sterilizersguidance on purchase, operation and maintenance. Publication no. MDA DB 2002(06). London: Medical Devices Agency, 2002

27. Andersen $H$ K, Fiehn N E, Larsen T. Effect of steam sterilization inside the turbine chambers of dental turbines. Oral Surg Oral Med Oral Path Oral Radiol Endod 1999; 87: 184-188.

28. Scully C, Smith A J, Bagg J. Prions and the human transmissible spongiform encephalopathies. Dent Clin North Am 2003; 47: 493-516.

29. Whittaker A G, Graham E M, Baxter R L et al. Plasma cleaning of dental instruments. J Hosp Infect 2004; 56: $37-41$

30. Department of Health. Advice for dentists on the re-use of endodontic instruments and variant Creuzfeldt-Jakob Disease (vCJD). London: Department of Health, 2007.

31. Medical Devices Agency. Single-use medical devices: implications and consequences of re-use. Publication no. DB 2006(04). London: Medical Devices Agency, 2006.

32. Leung R L, Schonfield S E. Gypsum casts as a potential source of microbial cross-contamination J Prosthet Dent 1983; 49: 210-211.

33. Al-Jabrah O, Al-Shumailan Y, Al-Rashdan M Antimicrobial effect of 4 disinfectants on alginate, polyether, and polyvinyl siloxane impression materials. Int J Prosthodont 2007: 20: 299-307.

34. Davenport J C. The denture surface. Br Dent J 1972; 133: 101-105

35. Cottone J A, Molinari J A. Selection for dental practice of chemical disinfectants and sterilants for hepatitis and AIDS. Aust Dent J 1987; 32: 368-374.

36. McNeill M R, Coulter W A, Hussey D L. Disinfection of irreversible hydrocolloid impressions: a comparative study. Int J Prosthodont 1992; 5: 563-567.

37. Beyerle M P, Hensley D M, Bradley D V Jr, Schwartz R S, Hilton T J. Immersion disinfection of irreversible hydrocolloid impressions with sodium hypochlorite. Part I: microbiology. Int J Prosthodont 1994; 7: 234-238

38. Taylor R L, Wright PS, Maryan C. Disinfection procedures: their effect on the dimensional accuracy and surface quality of irreversible hydrocolloid impression materials and gypsum casts. Dent Mater 2002: 18: 103-110.

39. Owen C P, Goolam R. Disinfection of impression materials to prevent viral cross contamination: a review and a protocol. Int J Prosthodont 1993: 6: $480-494$.

40. Department of Health. The controlled waste regulations. London: Department of Health, 1992.

41. Department of Health. The hazardous waste (England and Wales) regulations. London: Department of Health, 2005.

42. Scully C, Blake C, Griffiths M, Levers H. Protective wear and instrument sterilisation/disinfection in UK general dental practice. Health Trends 1994; 26: 21-22.

43. Georgescu C E, Skaug N, Patrascu I. Cross-infection in dentistry. Biotechnol Lett 2002; 7: 861-868.

44. Ayliffe G A J, Coates D, Hoffman P N. Chemical disinfection in hospitals. London: Public Health and Laboratory Services, 1984

45. Kugel G, Perry R D, Ferrari M, Lalicata P. Disinfection and communication practices: a study of $U \mathrm{~S}$ dental laboratories. J Am Dent Assoc 2000; 131: 786-792.

46. Gordon B L, Burke F J, Bagg J, Marlborough H S, McHugh E S. Systematic review of adherence to infection control guidelines in dentistry. J Dent 2001; 29: 509-516.

47. Davis D, BeGole E A. Compliance with infectioncontrol procedures among Illinois orthodontists. Am J Orthod Dentofacial Orthop 1998; 113: 647-654. 